\title{
Magnitude of Home Delivery and Associated Factors among Antenatal Care Booked Mothers in Delanta District, South Wollo Zone, North East Ethiopia: A Cross-Sectional Study, March 2018
}

\author{
Tilahun Wodaynew*, Bekana Fekecha" and Biru Abdisa ${ }^{\#}$
}

School of Nursing and Midwifery, Jimma University, Ethiopia

${ }^{\#}$ Equally Contributed.

*Corresponding author: Tilahun Wodaynew, School of Nursing and Midwifery, Jimma University, Ethiopia

\begin{abstract}
Background: Home delivery is childbirth in a non-clinical setting that takes place in residence than in health institution. Globally, every day more than 800 women died due to complications during pregnancy or childbirth. In Ethiopia, few are known about the factors that affect women's place of delivery after utilization of antenatal care service. Therefore, the aim of this study was to assess the magnitude of home delivery and associated factors among antenatal care booked mothers in Delanta district, North east Ethiopia.
\end{abstract}

Methods: A community-based Cross-sectional study design was conducted from March 15 to 30, 2018. Multistage sampling methods were applied to select 576 respondents among mothers booked for antenatal care. Data was collected through face to face interview using pretested questionnaire. Epi-Data version 3.1 and statistical package for social science (SPSS) version 21 were used for data entry and analysis respectively. Binary and multivariable logistic regression analyses were used to identify any statistically significant association existed between dependent and independent variables. P-value $<0.05$ was declared as statistical significance level.

Result: The prevalence of home delivery after ante natal care (ANC) follow up among mothers who gave birth in the last one year was $196(35.2 \%)$. The factors associated with home delivery were age of the mothers between 20-24 years $(\mathrm{AOR}=0.089,95 \% \mathrm{Cl}[0.043,0.184])$, occupation of the mothers $(A O R=3.422,95 \% \mathrm{Cl}[1.557,7.524])$, nonexposed to media (AOR $=1.979,95 \% \mathrm{Cl}[1.149,3.410]$ ), having first antenatal care) visit (AOR $=3.217,95 \% \mathrm{Cl}$ $[1.575,6.570])$ and distance (time taken) between 90-120 minutes to reach health facility on foot $(5.459,95 \% \mathrm{Cl}$ [1.681, 17.732])
Conclusion and recommendation: The magnitude of home delivery after ante natal care follow up in Delanta district was high. Distance, age and occupation of the mothers, number of ANC visit and non-media exposure were statistically significant association with home delivery. The district should better enhances geographic access to a health facility, gives awareness on the importance of media exposure and the health professionals should visit mothers if they miss the next appointment in ANC follow up care.

\section{Keywords}

Home delivery, Associated factors, Antenatal care, Delanta district

\begin{abstract}
Abbreviation
AIDS: Acquired Immune Deficiency Syndrome; ANC: Antenatal Care; AOR: Adjusted Odds Ratios; $\mathrm{Cl}$ : Confidence Interval; COR: Crudes Odds Ratios; EDHS: Ethiopian Demographic and Health Survey; HIV: Human Immunodeficiency Virus; MMR: Maternal Mortality Rate (MMR); OR: Odds Ratio; PPH: Postpartum Hemorrhage; TBA: Traditional Birth Attendants; WHO: World Health Organization
\end{abstract}

\section{Introduction}

Maternal morbidity and mortality is a global health challenge and developing countries contribute most of the maternal death [1]. According to the Maternal Mortality Estimation Inter-agency Group, developing countries accounted for approximately $99 \%$ of global maternal deaths in 2015 with $66 \%$ of these deaths occurring in sub-Saharan Africa. Developing countries

Citation: Wodaynew T, Fekecha B, Abdisa B (2018) Magnitude of Home Delivery and Associated Factors among Antenatal Care Booked Mothers in Delanta District, South Wollo Zone, North East Ethiopia: A Cross-Sectional Study, March 2018. Int J Womens Health Wellness 4:086. doi.org/10.23937/24741353/1510086

Accepted: December 11, 2018: Published: December 13, 2018

Copyright: (C) 2018 Wodaynew T, et al. This is an open-access article distributed under the terms of the Creative Commons Attribution License, which permits unrestricted use, distribution, and reproduction in any medium, provided the original author and source are credited. 
accounted with the maternal mortality ratio (MMR) of 239 per 100,000 live births, 20 times higher compared to the developed regions (12 maternal deaths per 100,000 live births) [2]. Despite an apparent global improvement made over the last two and half decades, the worldwide MM dropped by about $45 \%$ in 2015 , which is far from the decline targeted (75\%) to be achieved by 2015 [2,3]. Similarly, a recent Ethiopian demographic health Survey indicates maternal mortality ratio (MMR) is 412 per 100,000 live births [4]. Moreover, despite Ethiopia's 71.8\% decline in MMR between 1990 and 2015, the lifetime risk of maternal death remains alarmingly high with 1 in 64 women at risk of dying from maternal causes, taking into account other competing causes of death [5].

A vast majority of maternal deaths are due to preventable direct obstetric causes that can be detected and managed early during antenatal care (ANC) and intrapartum period by existing and well known medical interventions [6]. If home delivery is not conducted by professionals; it increases the risk of infection, postpartum hemorrhage (PPH), and transmission of HIV/AIDS to relatives or traditional birth attendants, who conduct deliveries without protective equipment's [7]. The burden of home delivery mainly that of unattended delivery is not only limited to maternal health problem, but it also ends up with perinatal and neonatal morbidity and mortality [8].

Ethiopia was a country where low proportion of reproductive age women visit skilled provider during pregnancy and childbirth [9]. Having antenatal care follow up does not mean that the deliveries of attended pregnancy will take place at health institution. A great majority (74\%) of women nationwide gave birth at home even though $62 \%$ of women attend antenatal care [4]. Moreover, low proportion of births was assisted by skilled attendant in some 4 areas of the country [10-12].

A community based cross sectional study conducted in Anlemo District, Southern Ethiopia revealed that (49.3\%) of mothers delivered at home while in Fogera district, Northwest Ethiopia, high magnitude of home delivery (68.4\%) (6\% were assisted by their relatives, $62.4 \%$ were attended by traditional birth attendants (TBAs)) took place at home among ANC booked women $[13,14]$. Another community-based quantitative cross sectional study was conducted in Debremarkos town revealed that $(25.3 \%)$ of women were delivered at home among ANC booked women [15]. The discrepancy between the proportions of deliveries in the health facility and at least four antenatal cares were remarkably high in Ethiopia [16]. Thus suggest, there is a greater gap between antenatal care visiting and institutional delivery. Therefore, the aim of this study is to assess the magnitude of home delivery and associated factors among antenatal care booked mothers who gave birth in the last 12 months in Delanta district, South Wollo zone, north east Ethiopia.

\section{Method}

\section{Study area and study period}

Delanta district is located in South Wollo zone, the Amhara regional state of Ethiopia which lies between $11^{\circ} 29^{\prime} 29.82^{\prime \prime}$ to $11^{\circ} 41^{\prime} 25.53^{\prime \prime} \mathrm{N}$ and $39^{\circ} 02^{\prime} 19.19^{\prime \prime}$ to $39^{\circ} 14^{\prime}$ 05.04" E with an altitude ranging from 1500 to 3819 meter above sea level at the bottom of the valleys (Gosh Meda) and the top of the mountain (Mekelet) respectively. It is situated about $499 \mathrm{~km}$ north of Addis Ababa and $98 \mathrm{~km}$ northwest of Dessie town in south Wollo zone. Based on the 2007 national census, Delanta district has 145,286 total populations out of which 28,285 are the total number of women of child bearing age (15-49 years). Majority of the populations are farmers and Christians. The woreda has one town with two kebeles and 32 rural kebeles (small administrative unit). In addition, there are one primary hospital, 6 health centers, and 32 Health posts in 32 kebeles. The study was conducted from March 15 to 30, 2018.

\section{Study design}

A community-based cross-sectional study design was conducted.

\section{Population}

Source population: All child bearing mothers (1549 years of age) who were booked for ANC and gave birth in the last one year in Delanta district, south Wollo zone, north east Ethiopia.

Study population: All sampled Antenatal Care Booked mothers who gave birth within one year (12 months) before data collection period in the selected kebeles.

\section{Sample size and sampling procedure}

Sample size: The sample size was determined by using a single population proportion formula considering the following assumptions: expected proportion of home delivery after booked for ANC (25.3\%) from previous study in Debre Markos [15], 95\% confidence interval and a margin of error of $5 \%$.

$Z \alpha / 2=$ Confidence interval at 95\% level (1.96)

$D=$ is the degree of precision (marginal error) $5 \%$

$$
\mathrm{n}=\frac{\left(\mathrm{Z}_{\mathrm{a} / 2}\right)^{2} \mathrm{p}(1-\mathrm{P})}{\mathrm{d}^{2}}
$$

Substitute the values in to the formula:

$N=(1.96)^{2} 0.253(1-0.253) /(0.05)^{2}=290$. Since the source population was less than 10,000 , using the correction formula:

$$
\mathrm{nf}=\frac{\mathrm{n}}{1+\frac{(\mathrm{n})}{\mathrm{N}}}=\frac{290}{1+\frac{(290)}{2759}}=262
$$


Using the above assumptions and considering design effect of 2 and $10 \%$ non-response rate:

The required final sample sizes became 576 .

Sampling technique and procedure: Multistage sampling method with stratification of the district into rural and urban areas was used based on residence. Delanta district has 32 rural and 2 urban kebeles, from those by taking $30 \%$ of the total kebeles (nine kebeles from the rural and one kebele from the urban) were selected by simple random sampling method. Those selected kebeles are named as (Arka, Goshmeda, Chewkutir, Chewdinga, Tardat, Ambaye, Asim, Tikurena, Ambaye and Ziban). The sample size was distributed to the ten kebeles by proportionate allocation to the size of their population. Mothers in the sampled kebeles selected by using simple random sampling technique (lottery method) based on the sampling frame obtained from health center and health extension workers.

\section{Data collection tools and procedures}

Data was collected using pretested, structured and semi-structured interviewer-administered questionnaire. The questionnaire was adapted from previous research [15]. Two days training were given for data collectors and supervisors. The questionnaire was administered through face to face interview by six [6] trained clinical nurses who were not working in the study area, and the data collection were strictly supervised by two bachelor health professionals (BSc. Nurse). Data was collected on daily basis (by using guidance from the selected kebeles who assist the data collectors) for the period of two weeks starting from March 15-30, 2018. Respondents who refused to participate in the study were included in the non-response rate and mothers in the next household would be considered in place of those who were not available upon frequent visits during data collection. Daily meeting was conducted between data collectors, supervisors and principal investigator for discussion regarding presenting difficulties and to assess the progress of data collection.

\section{Data quality control}

Data quality was ensured during data collection, coding, entry and analysis. The questionnaire translated to Amharic (local language) to obtain data from the study participants and to ensure understandability and clarity the contents properly. The questionnaire was back translated to English by an independent translator (language expert) to check the conceptual consistency of items. Prior to the actual data collection activities (one week prior to data collection), the instrument was pre-tested on 29 mothers ( $5 \%$ of sample size) from Dawunt district. After completing the pretest of the questionnaire, necessary changes (removal of some repeated questions and skipping patterns) was made based on the information obtained from participants to make questions more understandable and cronbanch alpha was done (which was 0.81). The completeness of the questionnaire and accuracy of the information recorded was checked at the end of each day by supervisors and principal investigator. Completeness of the collected data was finally reviewed by principal investigator prior to data entry.

\section{Data processing and analysis}

The data was entered by using the software Epi data version 3.1 and exported to Statistical Package for Social Sciences (SPSS) version 21 for analysis. All required variable recoding and transformation was done before the final data analysis. Binary logistic regression and multivariable logistic regression model used to identify any statistically significant association existed between dependent and independent variables. Variables having $p$-values less than 0.25 in the Binary analysis was fitted in to the multivariable logistic regression model. Ninety five percent confidence interval of odds ratio was computed and variable having P-value less than 0.05 in the multivariable logistic regression analysis was considered as significant associated factors for home delivery. Finally, findings were presented in text, tables and graphs.

\section{Ethical consideration}

The study was conducted after getting Ethical clearance from the Institutional Review Board of Institute of health, faculty of health science in Jimma University. Official letter of cooperation was also obtained from the health office of Delanta district and from all sampled Kebeles through a formal letter. Participants in the study were asked only on the voluntary basis. Written informed consent was obtained from each participant prior to the interview to confirm willingness after explaining the objective of the study. No personal identifiers of the study participants were undertaken hence all information obtained from the study participants had kept strictly confidential.

\section{Result dissemination plan}

A copy of the final report of this study will be given to school of Nursing and Midwifery, Institute of health, Faculty of Health science, Jimma University and Delanta district Health office. The findings will be presented in different seminars, meetings and workshops and may also be made publically accessible through publications in international reputable journals.

\section{Result}

\section{Sociodemographic characteristics of the study participants}

From a total of 576 study participants, 557 of them who had booked for antenatal care visit for their last pregnancy and gave birth within 1 year prior to the survey were interviewed which makes response rate of $96.7 \%$. About 193 (34.6\%) of the mothers were between the ages of 25 to 29 years. About 487 (87\%) of the moth- 
Table 1: Socio-demographic characteristics of the mothers in Delanta district, south Wollo, north east Ethiopia, March 2018.

\begin{tabular}{|c|c|c|}
\hline Variables & $\begin{array}{l}\text { Frequency } \\
(\mathrm{n}=557)\end{array}$ & $\begin{array}{l}\text { Percentage } \\
\text { (\%) }\end{array}$ \\
\hline \multicolumn{3}{|l|}{ Mothers age } \\
\hline $15-19$ & 26 & 4.7 \\
\hline $20-24$ & 119 & 21.4 \\
\hline 25-29 & 193 & 34.6 \\
\hline $30-34$ & 92 & 16.5 \\
\hline$>=35$ & 127 & 22.8 \\
\hline \multicolumn{3}{|l|}{ Religion } \\
\hline Orthodox & 492 & 88.3 \\
\hline Protestant & 10 & 1.8 \\
\hline Muslim & 55 & 9.9 \\
\hline \multicolumn{3}{|l|}{ Ethnicity } \\
\hline Amhara & 549 & 98.6 \\
\hline Tigre & 8 & 1.4 \\
\hline \multicolumn{3}{|l|}{ Marital status } \\
\hline Single & 26 & 4.7 \\
\hline Married & 486 & 87.3 \\
\hline Widowed & 13 & 2.3 \\
\hline Divorced & 17 & 3.0 \\
\hline Separated & 15 & 2.7 \\
\hline \multicolumn{3}{|l|}{ Occupation of the mothers } \\
\hline House wife & 206 & 37 \\
\hline Government employee & 98 & 17.6 \\
\hline Nongovernmental employee & 45 & 8 \\
\hline Private Business & 36 & 6.5 \\
\hline Student & 30 & 5.4 \\
\hline Farmer & 142 & 25.5 \\
\hline \multicolumn{3}{|c|}{ Household income in birr per month } \\
\hline$<=500$ & 15 & 2.7 \\
\hline $501-1000$ & 35 & 6 \\
\hline $1001-1500$ & 72 & 13 \\
\hline $1501-2000$ & 83 & 15 \\
\hline 2001-2500 & 98 & 18 \\
\hline $2501-3000$ & 104 & 18.6 \\
\hline$>3000$ & 121 & 21.7 \\
\hline I don't know & 29 & 5 \\
\hline \multicolumn{3}{|l|}{ Occupation of the husbands } \\
\hline Farmer & 322 & 57.8 \\
\hline Government employee & 137 & 24.6 \\
\hline Nongovernmental employee & 15 & 2.7 \\
\hline Student & 13 & 2.3 \\
\hline Private business & 70 & 12.6 \\
\hline \multicolumn{3}{|l|}{ Residency of the mothers } \\
\hline Urban & 70 & 13 \\
\hline Rural & 487 & 87 \\
\hline \multicolumn{3}{|l|}{ Mather's educational Level } \\
\hline Don't read and write & 168 & 30.2 \\
\hline Read and write & 137 & 24.6 \\
\hline Primary education & 77 & 13.8 \\
\hline Secondary education & 81 & 14.5 \\
\hline Above secondary & 94 & 16.9 \\
\hline \multicolumn{3}{|l|}{ Husbands' Educational Level } \\
\hline Don't read and write & 111 & 19.9 \\
\hline Read and write & 157 & 28.3 \\
\hline Primary education & 72 & 12.9 \\
\hline Secondary education & 76 & 13.6 \\
\hline Above secondary & 141 & 25.3 \\
\hline
\end{tabular}

Table 2: Reasons for delivering at home among mothers who gave birth in Delanta district, south Wollo, north east Ethiopia, March 2018.

\begin{tabular}{|c|c|c|}
\hline Home delivery reasons & $\begin{array}{l}\text { Frequency } \\
(n=196)\end{array}$ & $\begin{array}{l}\text { Percent } \\
(\%)\end{array}$ \\
\hline \multicolumn{3}{|c|}{$\begin{array}{l}\text { Institutional delivery is not } \\
\text { necessary }\end{array}$} \\
\hline Yes & 18 & 9.2 \\
\hline No & 178 & 90.8 \\
\hline \multicolumn{3}{|c|}{ Home delivery is our culture } \\
\hline Yes & 61 & 31.1 \\
\hline No & 135 & 68.9 \\
\hline \multicolumn{3}{|c|}{ Institutional delivery is too costly } \\
\hline Yes & 6 & 3.0 \\
\hline No & 190 & 97 \\
\hline \multicolumn{3}{|c|}{$\begin{array}{l}\text { Health professionals do not allow } \\
\text { family members to accompany in } \\
\text { labor ward }\end{array}$} \\
\hline Yes & 19 & 9.7 \\
\hline No & 177 & 90.3 \\
\hline \multicolumn{3}{|c|}{$\begin{array}{l}\text { Dislike behaviors of health workers } \\
\text { at health institution }\end{array}$} \\
\hline Yes & 21 & 10.7 \\
\hline No & 175 & 89.3 \\
\hline \multicolumn{3}{|c|}{$\begin{array}{l}\text { Too far health facility and lack of } \\
\text { transport }\end{array}$} \\
\hline Yes & 86 & 43.9 \\
\hline No & 110 & 56.1 \\
\hline \multicolumn{3}{|c|}{$\begin{array}{l}\text { More trust on TBA/relatives than } \\
\text { health workers }\end{array}$} \\
\hline Yes & 11 & 5.6 \\
\hline No & 185 & 94.4 \\
\hline \multicolumn{3}{|c|}{$\begin{array}{l}\text { Poor quality of service in health } \\
\text { institution }\end{array}$} \\
\hline Yes & 18 & 9.2 \\
\hline No & 178 & 90.8 \\
\hline \multicolumn{3}{|c|}{ Labor was simple and fast } \\
\hline Yes & 104 & 53.1 \\
\hline No & 92 & 46.9 \\
\hline \multicolumn{3}{|c|}{$\begin{array}{l}\text { Wishes to deliver at home where } \\
\text { relatives are nearby }\end{array}$} \\
\hline Yes & 19 & 9.7 \\
\hline No & 177 & 90.3 \\
\hline \multicolumn{3}{|c|}{ Husband/family don't allow } \\
\hline Yes & 16 & 8.2 \\
\hline No & 180 & 91.8 \\
\hline
\end{tabular}

ers were rural in residency while the remaining 70 (13\%) were from Urban. Most 549 (98.6\%) of the mothers belongs to Amhara by ethnicity and 492 (88.3\%) Ethiopia orthodox tewahido by religion. Regarding the marital status, $486(87.3 \%)$ of the mothers were married. With regard to occupation, majority of the mothers and their husbands were house wife 206 (37\%) and farmer 322 (57.8\%) respectively. Concerning the educational level, $168(30.2 \%)$ of the mothers were not educated but majority $157(28.2 \%)$ of their husbands could read and write (see on Table 1).

\section{Home delivery and reasons given}

The prevalence of home delivery after ante natal care follow up among mothers who gave birth in the last 
one year was 196 (35.2\%). Of the total home deliveries, $128(65.3 \%)$ of them were assisted by non-traditional birth attendants and 68 (34.7\%) of these deliveries were attended by relatives. Mothers gave a variety of reasons for using home delivery. Among these labor was simple and fast 104 (53.4\%), Too far health facility and lack of transport $86(43.9 \%)$ and Home delivery is our culture 61 (31\%) were leading reasons (see on Table 2).

The majority 525 (94.3\%) of the mothers had geographic access for health facility in the Village, among these $378(73.5 \%)$ could be reached within 30 60 minutes on foot (see on Figure 1). Nearly half (49.7\%) of the mothers were exposed to at least one means of media per week (see on Table 3).

\section{Past obstetrics characteristics of the respondents}

About 335 (60.1\%) of mothers were married when they were between $15-19$ years of age while $242(43.4 \%)$ of the mothers had their first pregnancy between the ages of 20-24 years and majority of the participants 305

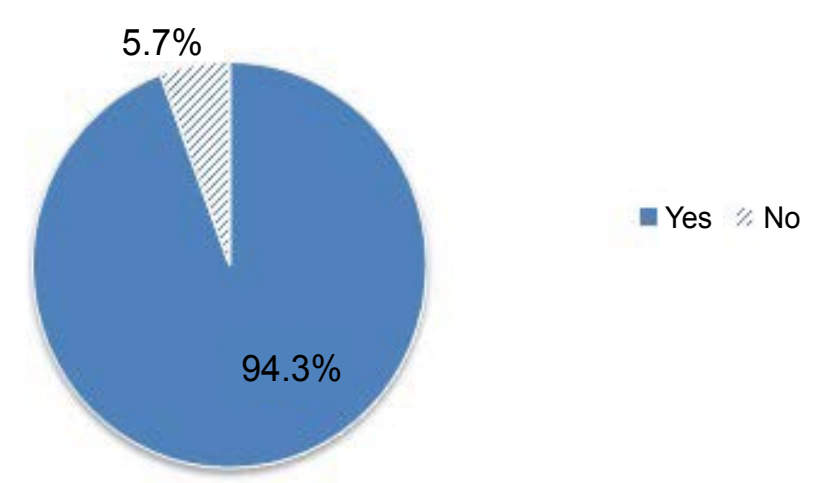

Figure 1: Presence of nearby health center or hospital of the mothers in Delanta district, south Wollo, north east Ethiopia, March 2018.

Table 3: Distribution of media exposure among mothers in Delanta district, south Wollo, north east Ethiopia, March 2018.

\begin{tabular}{|l|l|l|}
\hline Media exposure & $\begin{array}{l}\text { Frequency } \\
\text { (n= 557) }\end{array}$ & $\begin{array}{l}\text { Percent } \\
\text { (\%) }\end{array}$ \\
\hline $\begin{array}{l}\text { Reads a newspaper at least once a } \\
\text { week }\end{array}$ & 12 & 2.2 \\
\hline Yes & 545 & 97.8 \\
\hline $\begin{array}{l}\text { No } \\
\text { Watches television at least once a } \\
\text { week }\end{array}$ & & \\
\hline Yes & 80 & 14.3 \\
\hline No & 477 & 85.7 \\
\hline Listens radio at least once a week & & \\
\hline Yes & 140 & 25.1 \\
\hline No & 417 & 74.9 \\
\hline $\begin{array}{l}\text { Accesses all three media at least } \\
\text { once a week }\end{array}$ & & \\
\hline Yes & 45 & 8.1 \\
\hline No & 512 & 91.9 \\
\hline $\begin{array}{l}\text { Accesses none of the three media } \\
\text { at least once a week }\end{array}$ & & \\
\hline Yes & 265 & 47.6 \\
\hline No & 292 & 52.4 \\
\hline
\end{tabular}

(54.8\%) and 309 (55.5\%) had 2-4 number of gravidity and parity respectively. $418(75 \%)$ of the mothers had no previous history of prolonged labor (Figure 2 and Table 4).

Regarding their last pregnancy, 452 (81\%) mothers reported that their last pregnancy were planned (see on Figure 3).

Majority (68.9\%) of the mothers attend ANC visits at health center (see on Figure 4). Only 139 (25\%) of the mothers were attended four and above visits of antenatal care (see on Figure 5). About 185 (33.2\%) of the mothers visited first ANC between 16-20 weeks (see on Table 5).

\section{Perceived characteristics of ANC and knowledge of the participants}

The majority $502(90.1 \%)$ and $494(88.7 \%)$ of the

Table 4: Distribution past obstetrics history of the mothers in Delanta district, south Wollo, north east Ethiopia, March 2018.

\begin{tabular}{|l|l|l|}
\hline Variables & $\begin{array}{l}\text { Frequency } \\
\text { (n= 557) }\end{array}$ & $\begin{array}{l}\text { Percent } \\
\text { (\%) }\end{array}$ \\
\hline Age at first marriage & & \\
\hline $\mathbf{1 5 - 1 9}$ & 335 & 60.1 \\
\hline $\mathbf{2 0 - 2 4}$ & 133 & 23.9 \\
\hline $\mathbf{2 5 - 2 9}$ & 23 & 4.1 \\
\hline $\mathbf{3 0 - 3 4}$ & 1 & - \\
\hline I don't know & 65 & 11.7 \\
\hline Age at first pregnancy & & \\
\hline $\mathbf{1 5 - 1 9}$ & 182 & 32.7 \\
\hline $\mathbf{2 0 - 2 4}$ & 242 & 43.4 \\
\hline $\mathbf{2 5 - 2 9}$ & 65 & 11.7 \\
\hline $\mathbf{3 0 - 3 4}$ & 1 & - \\
\hline $\mathbf{> =} \mathbf{3 5}$ & 2 & - \\
\hline I don't know & 65 & 11.7 \\
\hline & & \\
\hline Gravida of the mothers & & \\
\hline $\mathbf{1}$ & 168 & 30.2 \\
\hline $\mathbf{2 - 4}$ & 305 & 54.8 \\
\hline $\mathbf{5}$ and above & 84 & 15.1 \\
\hline Parity of the mothers & & \\
\hline $\mathbf{1}$ & 167 & 30.0 \\
\hline $\mathbf{2 - 4}$ & 309 & 55.5 \\
\hline $\mathbf{5}$ and above & 81 & 14.5 \\
\hline Have you experienced & & \\
\hline prolonged labor? & & 25 \\
\hline Yes & 139 & \\
\hline No & 418 & \\
\hline & & \\
\hline
\end{tabular}

Table 5: The gestational age at first ANC visit of the mothers in Delanta district, South Wollo, north east Ethiopia, March 2018.

\begin{tabular}{|l|l|l|}
\hline Variable & Frequency & Percent (\%) \\
\hline Gestational age at first ANC visit? & & \\
\hline$<16$ weeks & 172 & 30.9 \\
\hline$[16-20]$ weeks & 185 & 33.2 \\
\hline$[20-24]$ weeks & 97 & 17.4 \\
\hline$[24-28]$ weeks & 46 & 8.3 \\
\hline [28-32] weeks & 29 & 5.2 \\
\hline >= 32 weeks & 17 & 3.1 \\
\hline I don't know & 11 & 2.0 \\
\hline
\end{tabular}




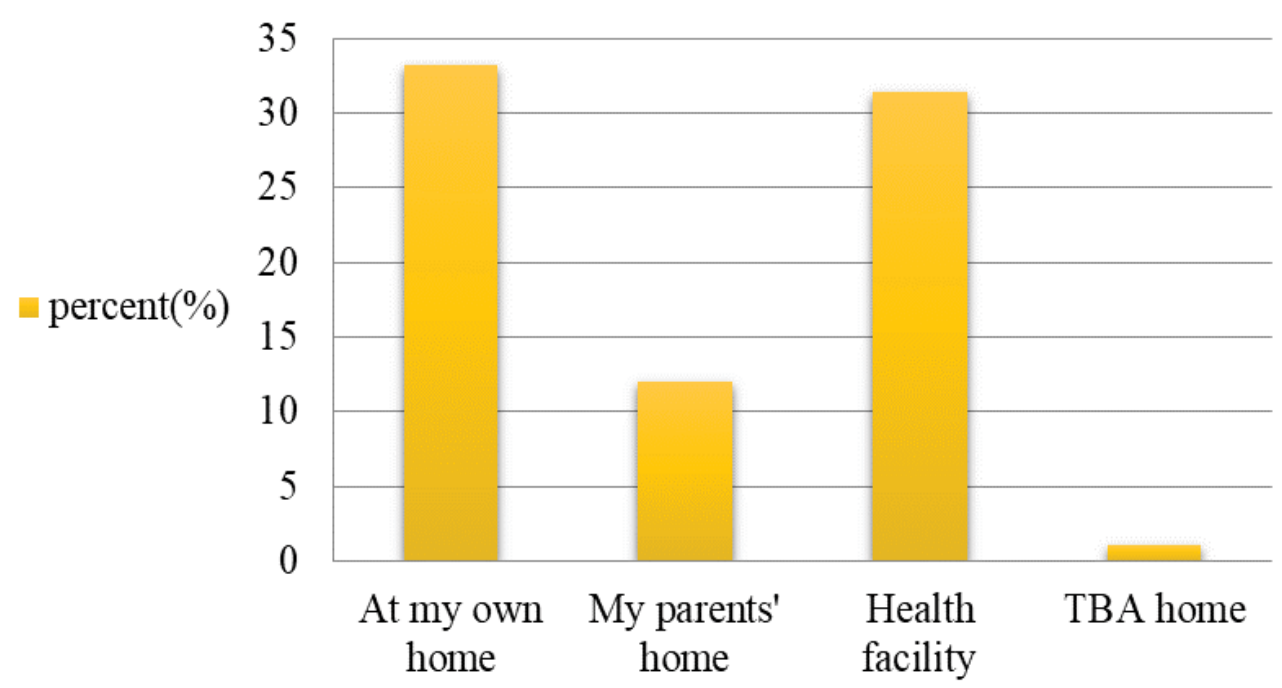

Figure 2: Birth place of previous last child of the mothers in Delanta district, south Wollo, north east Ethiopia, March 2018.

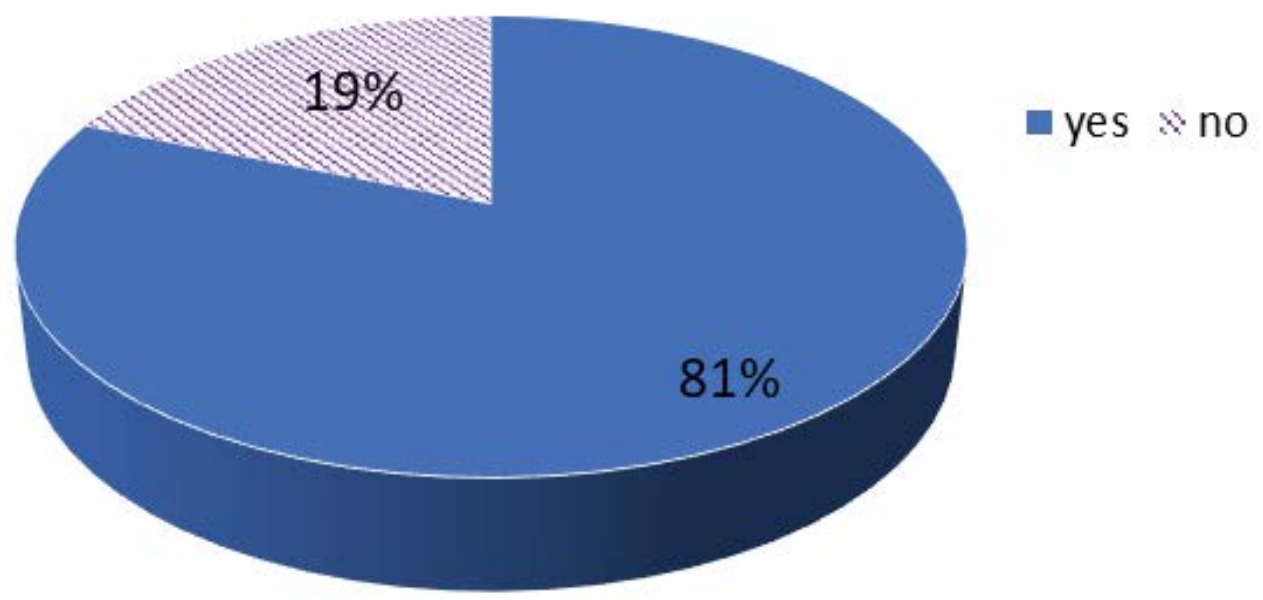

Figure 3: Distribution of last planned pregnancies of the mothers in Delanta district, south Wollo, north east Ethiopia, March 2018.

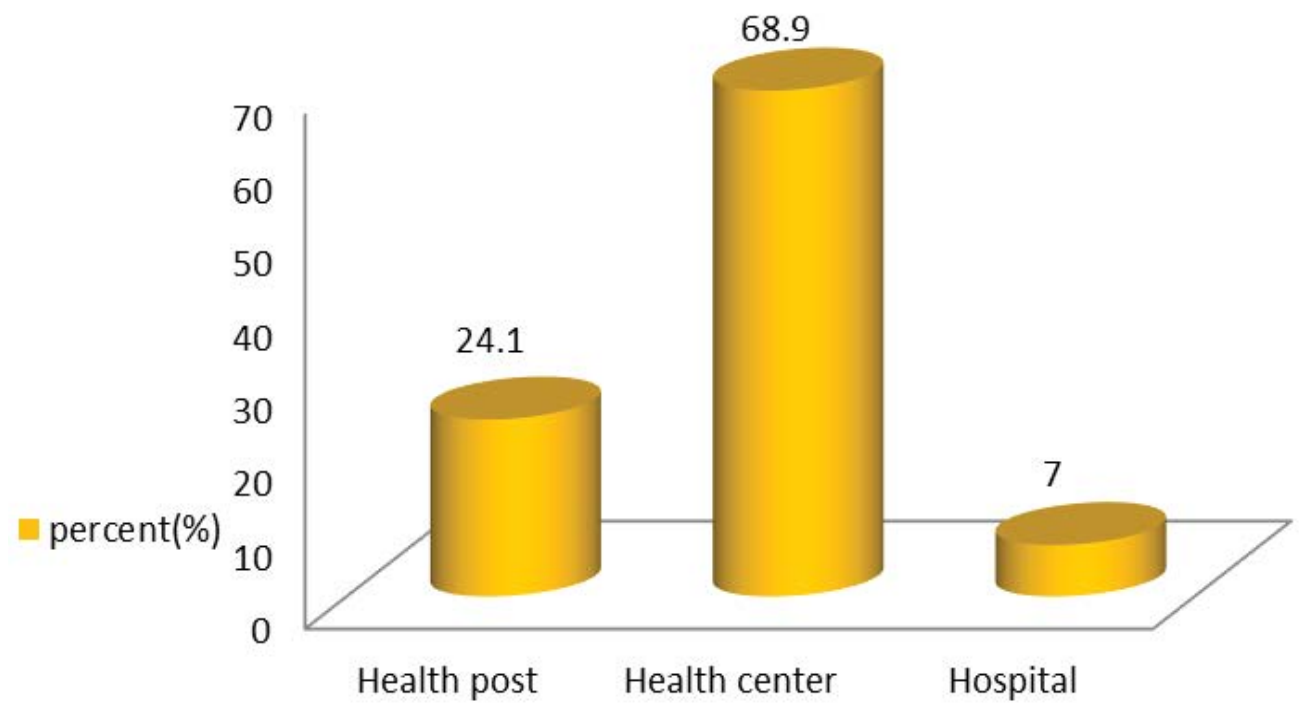

Figure 4: Place of ANC visit of the mothers in Delanta district, south Wollo, north east Ethiopia, March 2018.

mothers reported that they received an explanation from health care providers about their health condition and what to expect during labor and delivery respectively. Similarly, 516 (92.6\%) and 498 (89.4\%) 


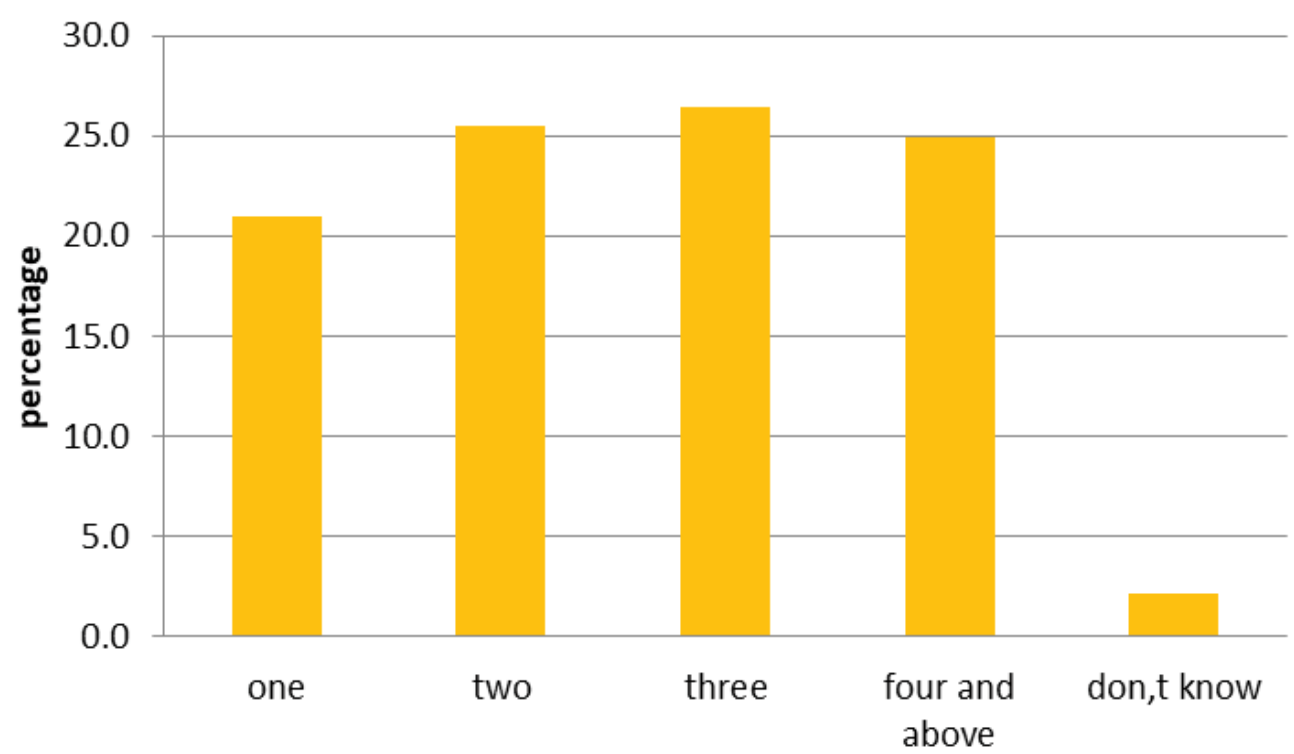

Figure 5: Number of ANC visits of the mothers in Delanta district, south Wollo, north east Ethiopia, March 2018.

Table 6: Counseling and communication with health providers during ANC among mothers in Delanta district, south Wollo, north east Ethiopia March 2018.

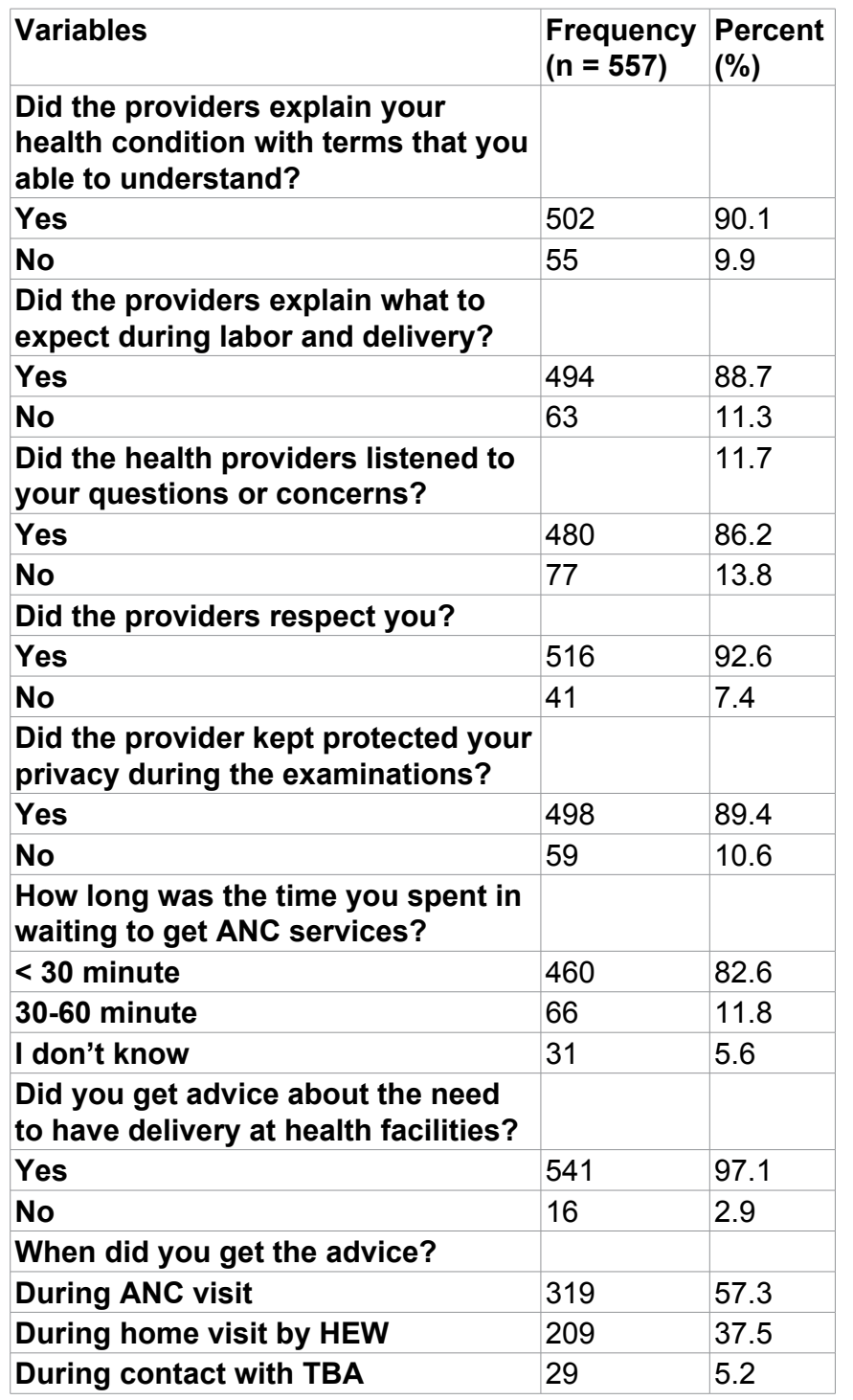

reported that they received respect and privacy from the service provider during antenatal care respectively (see on Table 6).
Among 34 knowledge questions mothers were asked on danger sign, maternity services, and complications during pregnancy and delivery. The respondents classified as had good knowledge and poor knowledge, taking the mean score (10.6) as differentiation for knowledge. $263(47.2 \%)$ of the mothers had good knowledge, while $294(52.8 \%)$ of them had poor knowledge.

\section{Maternal decision power on health care}

459 (82.4\%) of mothers reported that they have discussed with their husbands about the place of delivery and majority 403 (72.4\%) of them preferred to deliver at health facility while comparably 425 (76.3\%) of husbands preferred the same place. Regarding delivery attendant 54 (9.7\%) of mothers and 59 (10.6\%) of husbands preferred non- trained TBA and one of family members respectively. $378(67.9 \%)$ of the final decision regarding the place of delivery was given by both the mothers and their husbands, while 107 (19.2\%) of the mothers gave decision by themselves on the place of delivery. 116 (20.8\%) and 402 (72.2\%) of a financial decision for costs related to pregnancy and delivery were decided only by their husbands and both the mothers and their husbands respectively.

\section{Factors associated with home delivery}

In Bivariable logistic regression maternal age, maternal occupation, husband occupation, maternal residence, maternal educational level, husband educational level, distance (time taken) to reach of health facility on foot, non-media exposure, number of delivery, experience of prolonged labor, planned pregnancy, number of ANC visit completed, maternal knowledge, privacy during ANC examination, waiting time to get ANC services in minutes and decision maker on cost needed for referral were the factors found to have Statistically significant association with home delivery. 
Table 7: Factors associated with home delivery among mothers in Delanta district, south Wollo, north east Ethiopia, March 2018 (from multivariable logistic regression analysis).

\begin{tabular}{|c|c|c|c|c|c|}
\hline \multirow[t]{2}{*}{ Variables } & \multicolumn{2}{|c|}{ Place of delivery } & \multirow{2}{*}{$\begin{array}{l}\text { COR } \\
(95 \% \mathrm{Cl})\end{array}$} & \multirow{2}{*}{$\begin{array}{l}\text { AOR } \\
(95 \% \mathrm{Cl})\end{array}$} & \multirow[t]{2}{*}{ P-value } \\
\hline & Home delivery & Health facility & & & \\
\hline \multicolumn{6}{|l|}{ Age of the mothers } \\
\hline $15-19$ & 15 & 11 & $0.539[0.226,1.286]$ & $0.417[0.142,1.230]$ & 0.113 \\
\hline $20-24$ & 19 & 100 & $0.075[0.040,0.140]^{* *}$ & $0.089[0.043,0.184]$ & $0.001^{*}$ \\
\hline $25-29$ & 18 & 175 & $0.041[0.022,0.076]$ & $0.042[0.020,0.089]$ & 0.102 \\
\hline $30-34$ & 53 & 39 & $0.538[0.305,0.946]$ & $0.373[0.183,0.759]$ & 0.206 \\
\hline$>=35$ & 91 & 36 & 1 & 1 & \\
\hline \multicolumn{6}{|l|}{$\begin{array}{l}\text { Occupation of the } \\
\text { mothers }\end{array}$} \\
\hline Housewife & 108 & 88 & $7.364[3.914,13.85]^{* *}$ & $3.422[1.557,7.524]$ & $0.002^{*}$ \\
\hline Farmer & 40 & 96 & $2.875[1.477,5.596]$ & $1.476[0.634,3.439$ & 0.367 \\
\hline $\begin{array}{l}\text { Nongovernment } \\
\text { employee }\end{array}$ & 12 & 41 & $0.585[0.181,1.890]$ & $0.312[0.081,1.207]$ & 0.092 \\
\hline Private business & 10 & 30 & $1.200[0.423,3.406]$ & $1.104[0.327,3.729]$ & 0.873 \\
\hline Student & 12 & 22 & $4.909[2.116,11.388]$ & $5.290[1.674,22,16.71]$ & 0.205 \\
\hline Government employee & 14 & 84 & 1 & 1 & \\
\hline \multicolumn{6}{|c|}{$\begin{array}{l}\text { Number of ANC visit } \\
\text { received? }\end{array}$} \\
\hline One & 74 & 61 & $3.7[2.240,6.265]^{\star \star}$ & $3.217[1.575,6.570]$ & $0.001^{*}$ \\
\hline Two & 56 & 83 & $1.860[1.104,3.136]$ & $1.066[0.515,2.205]$ & 0.863 \\
\hline Three & 31 & 105 & $0.932[0.536,1.621]$ & $0.552[0.264,1.157]$ & 0.115 \\
\hline I don't know & 11 & 11 & $3.088[0.934,10.211]$ & $4.663[1.020,21.329]$ & 0.47 \\
\hline Four and above & 34 & 101 & 1 & 1 & \\
\hline \multicolumn{6}{|l|}{$\begin{array}{l}\text { How much time it } \\
\text { take to reach Health } \\
\text { facilities }=525\end{array}$} \\
\hline$<30$ minutes & 45 & 145 & 1 & 1 & \\
\hline $30-60$ minutes & 49 & 125 & $1.310[0.823,2.087]$ & $0.625[0.333,1.173]$ & 0.143 \\
\hline $60-90$ minutes & 31 & 32 & $3.186[1.755,5.783]$ & $1.604[0.682,3.774]$ & 0.279 \\
\hline $90-120$ minutes & 21 & 11 & $8.633[3.58,20.814]^{* *}$ & $5.459[1.681,17.732]$ & $0.005^{*}$ \\
\hline$>120$ minutes & 22 & 21 & $3.759[1.916,7.375]$ & $1.379[0.384,4.955]$ & 0.622 \\
\hline I don't know & 12 & 11 & $3.289[1.168,9.261]$ & $2.120[0.864,5.201]$ & 0.101 \\
\hline \multicolumn{6}{|l|}{$\begin{array}{l}\text { Media exposure at } \\
\text { least once a week }\end{array}$} \\
\hline No & 129 & 151 & $2.678[1.865,3.845]^{* *}$ & $1.979[1.149,3.410]$ & $0.014^{*}$ \\
\hline Yes & 67 & 210 & 1 & 1 & \\
\hline
\end{tabular}

Notes: ${ }^{*}=\mathrm{P}<0.05$ values indicate statistically significant associations on multivariable analysis.

${ }^{*}=\mathrm{P}<0.01$ values indicate statistically significant associations on Bivariable analysis.

$1=$ Reference.

From the multivariate analysis, variables with $p$-value less than 0.05 were used to fit the final multivariable logistic regression model. At multivariable logistic regression analysis by using backward likelihood ratio and after adjusting for each other, revealed that five variables that were independent predictors for the magnitude of home delivery were maternal age $(A O R=0.089,95 \% \mathrm{Cl}$ $[0.043,0.184]$ ), number of ANC visit ( AOR $=3.217,95 \%$ $\mathrm{Cl}[1.575,6.570])$, Occupation of the mothers(AOR = $3.422,95 \% \mathrm{Cl}[1.557,7.524])$, time taken to reach Health facilities on foot $(5.459,95 \% \mathrm{Cl}[1.681,17.732])$ and nonmedia exposure (AOR $=1.979,95 \% \mathrm{Cl}[1.149,3.410])$.

Mothers who were between 20-24 years old were 91\% less likely to deliver at home than mothers having age of greater than 35 -years-old (AOR $=0.089,95 \% \mathrm{Cl}$ $[0.043,0.184])$. Mothers whose occupation housewife were 3.4 times more likely to deliver in their home than mothers who were government employee (AOR = $3.422,95 \% \mathrm{Cl}[1.557,7.524])$. Mothers who were visited ANC once time were 3 times more likely to deliver at home than mothers who had four and above ANC visit (AOR $=3.217,95 \% \mathrm{Cl}[1.575,6.570])$. Mothers who were traveling to reach health facility on foot between 90120 minutes were 5.5 times more likely gave birth at home than mothers who were traveling to reach health facility on foot within 30 minutes (AOR $=5.459,95 \%$ $\mathrm{Cl}[1.681,17.732])$. Mothers who were not exposed to media once a week were two times more likely to give delivery at home than mothers who were exposed to media once a week $(A O R=1.979,95 \% \mathrm{Cl}[1.149,3.410])$ (on Table 7).

\section{Discussion}

This community based cross sectional study has 
attempted to assess the magnitude of home delivery and associated factors among ANC booked mothers and gave birth in the last 12 months preceding the survey. The study results showed that the magnitude of Home delivery was 196 (35.2\%) of total study participants given delivery at home after having ANC visit. The magnitude of home delivery in this study lower than delivery conducted by unskilled provider in 2016 EDHS report $(72.3 \%)$ National and $72.3 \%$ of Amhara region [4]. The possible reason for the variation might be due to the fact that difference in study area and source of population in addition to this; currently the government and other supporting organizations are working strongly to increase institutional delivery service utilization.

The magnitude of home delivery in this study is also lower than the studies which were done in fogera district, north west Ethiopia, Anelemo woreda (49.3\%) and Arbaminch Zuria district in southern Ethiopia $(75.2 \%)[13,14,17]$. This might be due to the fact that maternal health is one of the sustainable development goal in which a lot of contributions had been made by the government and non-governmental organization to change the awareness of women's and communities' on the utilization of institutional delivery which might result in this study decreased home delivery than these studies mentioned above. The magnitude of home delivery in this study is also lower than the studies done in other developing countries conducted in Nigeria (40\%) and Kenya $(51.8 \%)$ [18,19]. This could be due to the presence of a difference in the health Service delivery system, socio-cultural difference, economic or study area setting difference. But this result is higher in the study conducted in Debre Markos town (25.3\%), in northern west Ethiopia and shashemen (19\%) in central part of Oromia region, Ethiopia $[15,20]$. This might be due to difference in study area and in addition the difference in source population since these studies were conducted at zonal level and this study conducted at Woreda level.

Age of the mothers was one of the predictor for home delivery; Mothers who were between 20-24 years old were $91 \%$ less likely to deliver at home than mothers having age greater than 35-years-old (AOR = $0.089,95 \% \mathrm{Cl}[0.043,0.184]$. This finding is similar with the findings reported in the studies conducted in Banja district in Awi zone, Dejen and Benchi-maji zone. The possible explanations might be that younger mothers are more likely to be educated and got better access of information to utilize modern health care facilities than home $[12,21,22]$.

Number of antenatal care visit had a strong significant association with home delivery. Mothers who were visited ANC once time were about three times more likely to deliver at home than mothers who had four and above ANC visit (AOR = 3.217, 95\% Cl [1.575, 6.570]. This result is in line with studies done in Dejen and fogera
$[14,21]$. This probably due to the fact that mothers who had one ANC visit didn't have better number of contact with skilled health care provider during pregnancies, especially on the place of delivery in later gestational age and with increased number of ANC visits, which gave chance for the mothers to know more about the importance of skilled attendant during childbirth and because of this, they couldn't have influenced their decision to deliver in health facility. Hence, ANC is the most favorable contact point for mothers to get more information about the risks and problems they may encounter during delivery.

Traveling time (distance) needed to reach to the nearby health institution which was another factor associated with home delivery. Mothers who were traveling to reach health facility on foot between 90120 minutes were 5.5 times more likely gave birth at home than mothers who were traveling to reach health facility on foot within 30 minutes $(5.459,95 \% \mathrm{Cl}$ [1.681, 17.732]). This result was consistent with Debre markos, Arbaminch, chiha district and Dangila [15,17,23,24]. The probable reason might be due to the fact that, When the health institution is found more farther, the cost needed to get the health care services would like to be also increase and she might not get better social support and transportation because people is travelled a long distance accompanying or carrying her. Walking a long distance is difficult in labor and impossible if labor start at night and means of transport are often not available and they enforced to choose home delivery. Besides this, far distance and lack of transport were the mothers' reason for home delivery.

Occupations of mothers were also another factor associated with home delivery. Mothers whose occupation housewife were three times more likely to deliver in their home than mothers who were government employee $(\mathrm{AOR}=3.42,95 \%, \mathrm{Cl}$ [1.557, 7.524]). This is in agreement with the studies done on gozamin district northwest Ethiopia and west pokot in Kenya $[25,26]$.

The possible explanation might be housewife had less awareness regarding complication of pregnancy and unaware of dangerous situations during child birth since they spend most of their time at home and the other possible reason might be the mothers' labor were simple and fast in this study.

Mothers who were not exposed to media once a week were two times more likely to give delivery at home than mothers who were exposed to media once a week $(A O R=1.979,95 \% \mathrm{Cl}[1.149,3.410])$. This is consistent with the studies done in Debre markos and Ethiopia. This could be due to the fact that mothers who have not media exposure didn't attend the awareness information on the importance of institutional delivery because mass media are effective in information dissemination, which could facilitate behavioral changes 
that might be allowing mothers for the acceptance and utilization of maternal health service. Media also have the ability to change the attitudes of mothers and communities used to have on home delivery, consequently mothers who were not exposed to any source of media might be continued having home delivery $[15,27,28]$.

\section{Strength and Limitation of the Study}

The main strength of this study is that, being community based, it could reflect the actual experience of the mothers during the study period (including both urban and rural areas). The findings of this study used a semi-structured questionnaire and findings are generalizable to the woreda. However, cross sectional nature of the study and the study included mothers who gave birth one year preceding the survey, there might be a recall bias.

\section{Conclusion and Recommendation}

The magnitude of home delivery in this study among mothers who were booked for antenatal care and gave childbirth within 1 year prior to survey time was high. Distance (time taken) to reach health facility on foot, age and occupation of the mothers, number (frequency) of ANC visit and non-media exposure are found to have statistically significant association with home delivery. The district health office considers and implement WHO recommendation that all pregnant mothers should be visited if they miss the next appointment in ANC follow up care. They Create or give awareness on the importance of media and promotion of institutional delivery service utilization through mass media. The district should better enhance geographic access to a health facility. Health professionals and health extension workers should give awareness on institutional delivery and on birth preparedness to deliver at health facility even on the sudden onset of labor and should give special attention and follow mothers who are housewife and living far distance. Researchers will do prospective (follow up) and case control study.

\section{Competing Interests}

The authors declare that they have no competing interests.

\section{Authors' Contributions}

Tw involved in designing of the study, data collection, data analysis, drafting and critically reviewing the manuscript. Likewise, BF and BA commented in designing of the study, analysis of the data and critically reviewing the manuscript. All authors read and approved the final manuscript.

\section{Consent for Publication}

Consent for publication is not applicable since there are no details, images, or videos relating to an individual person in this study.

\section{Funding}

This study was funded by Jimma University in partial fulfillment of the requirement for masters of Science degree in maternity health nursing.

\section{Author Details}

Tilahun Wodaynew is lecturer of maternal health nursing in Jimma University, Bekana Fekecha is assistant professor of in maternity health Nursing and PHD follower in Jimma University and Biru Abidisa is lecturer of clinical midwifery in Jimma University. All authors are currently staff members of school of Nursing and Midwifery in Jimma University.

\section{Acknowledgment}

My sincere and deepest gratitude goes to my advisors to Mr. Bekana Fekecha and Mr. Biru Abidisa for their timely and constructive comments. I would like to thank Jimma University for financial support and for free internet access for searching different literatures to prepare the thesis. My special thanks also goes to data collectors and supervisors who sacrified their valuable time to gather all the necessary information and Delanta district health office and all study participants including kebeles and villages leaders deserve special thanks for their cooperation and support during the study period.

\section{References}

1. WHO (2012) Maternal mortality.

2. WHO, UNICEF, UNFPA WBG and the UNPD (2015) Trends in maternal mortality: 1990 to 2015.

3. WHO, UNICEF, UNFPA WBG and the UNPD (2013) Trends in maternal mortality: 1990 to 2013.

4. Central statistical agency (2016) Ethiopia Demographic and Health Survey, key indicator report. 136.

5. Report S, By S (2016) Executive FOR, Ministry of Health R. Federal Democratic Republic Ethiopia. 16.

6. (2010) Federal Democratic Republic of Ethiopia Ministry of health. Management protocol on selected obstetrics topics (FMOH). 8-14.

7. Belemsaga DY (2015) A review of factors associated with the utilization of healthcare services and strategies for improving postpartum care in Africa. Afrika Focus. 28: 83105.

8. Chinkhumba J, De Allegri M, Muula AS, Robberstad B (2014) Maternal and perinatal mortality by place of delivery in sub-Saharan Africa: A meta-analysis of population-based cohort studies. BMC Public Health 14: 1014.

9. Wang W, Alva S, Wang S, Fort A (2011) Levels and trends in the use of maternal health services in developing countries. DHS Comparative Reports 26: 2-6.

10. Tsegay Y, Gebrehiwot T, Goicolea I, Edin K, Lemma H, et al. (2013) Determinants of antenatal and delivery care utilization in Tigray region, Ethiopia: A cross-sectional study. Int J Equity Health 12: 30.

11. Awoke W, Muhammed J, Abeje G (2013) Institutional delivery service utilization in Woldia, Ethiopia. Sci J Public Heal 1: 18-23. 
12. Wolelie A, Aychiluhm M, Awoke W (2013) Institutional delivery service utilization and associated factors in Banja District, Awie Zone, Amhara Regional. Open J Epidemiol 4: 30-35.

13. Shabeza AI, Tilahun BH, Markos SJ, Eshetu Y (2017) Analyzing prevalence of home delivery and associated factors in Anlemo District, Southern Ethiopia. Int Ann Med 1: $1-6$.

14. Endalkachew D, Alemtsehay M, Gedefaw A (2014) Place of delivery after antenatal care : The case of Fogera District, North West, Ethiopia. J Gynecol Obstet 2: 1-6.

15. Habtamu KK, Zerfu ME, Temesgen WG, Melese SD (2016) Home delivery among antenatal care booked women in their last pregnancy and associated factors: Communitybased cross sectional study in Debremarkos town, North West Ethiopia, January 2016. BMC Pregnancy Childbirth 17: 1-5.

16. Berhan Y, Berhan A (2014) Antenatal care as a means of increasing birth in the health facility and reducing maternal mortality: A systematic review. Ethiop J Health Sci 24: 93104.

17. Gistane A, Maralign T, Behailu M, Worku A, Wondimagegn $T$ (2015) Prevalence and associated factors of home delivery in Arbaminch Zuria district, Southern Ethiopia. Sci J Public Heal 3: 6-9.

18. Envuladu EA, Agbo HA, Lassa S, Kigbu JH, Zoakah AI (2013) Factors determining the choice of a place of delivery among pregnant women in Russia village of Jos North, Nigeria: Achieving the MDGs 4 and 5. Int $\mathrm{J}$ Med Biomed Res 2: 23-27.

19. Wanjira C, Mwangi M, Mathenge E, Mbugua G, Ng'ang'a Z (2011) Delivery practices and associated factors among mothers seeking child welfare services in selected health facilities in Nyandarua South District, Kenya. BMC Public Health 11: 360.
20. Teklemariam G, Biresaw W, Mekdes K, Besufekad B (2016) Home delivery and associated factors among reproductive age women in Shashemene Town, Ethiopia. J Womens Heal Care 5: 1-4.

21. Melaku D, Temesgen G, Tebikew $Y$, Yewbmirt S, Mulugeta A, et al. (2016) Determinants of institutional delivery among mothers who gave birth in the last one year in Dejen Woreda, Ethiopia. J Fam Med Heal Care 3: 45-51.

22. Fira A, Tariku TB (2016) Delivery site preferences and associated factors among married women of child bearing age in Bench Maji Zone, Ethiopia. Ethiop J Health Sci 26: 45-54.

23. Yeshalem MD, Gebremedhin BG, Azezu AN (2016) Factors associated with institutional delivery in Dangila district, North West Ethiopia: A cross-sectional study. Afr Health Sci 16: 10-17.

24. Habte F, Demissie M (2015) Magnitude and factors associated with institutional delivery service utilization among childbearing mothers in Cheha district, Gurage zone, SNNPR, Ethiopia: A community based cross sectional study. BMC Pregnancy and Childbirth 15: 1-5.

25. Ogolla JO (2015) Factors associated with home delivery in West Pokot County of Kenya. Adv Public Heal 2015: 1-6.

26. Mekonnen Y, Ayichiluhm M, Dejenu G (2015) Prevalence and determinants of home birth after antenatal care attendance in Gozamin District, Northwest Ethiopia. Heal Sci J 9: 1-7.

27. Resom T, Alemseged A, Kalayu K, Mussie A, Gebrezigabiher Y (2014) Determinant factors of home delivery among women in Northern Ethiopia: A case control study. BMC Public Health 17: 1-8.

28. Alemi K, Kalkidan H, Aderajew NT (2016) Factors associated with institutional delivery service utilization in Ethiopia. Int J Womens Health 8: 463-475. 